\title{
Sacral hemangioblastoma in a patient with von Hippel-Lindau disease
}

\author{
Case report and review of the literature
}

\author{
Ryszard M. Pluta, M.D., Scott D. Wait, B.A., John A. Butman, M.D., \\ Kathleen A. LepPig, M.D., AleXander O. VortMeyer, M.D., \\ EDWARd H. OLdFIELd, M.D., AND RuSSEll R. LONSER, M.D.
}

\begin{abstract}
Surgical Neurology Branch, National Institute of Neurological Disorders and Stroke; Section of Neuroradiology, Diagnostic Radiology Department, Clinical Center, National Institutes of Health, Bethesda, Maryland; and Genetic Services, Group Health Permanente, Seattle, Washington
\end{abstract}

\begin{abstract}
Hemangioblastomas are histologically benign neoplasms that occur sporadically or as part of von Hippel-Lindau disease. Hemangioblastomas may occur anywhere along the neuraxis, but sacral hemangioblastomas are extremely rare. To identify features that will help guide the operative and clinical management of these lesions, the authors describe the management of a large von Hippel-Lindau disease-associated sacral hemangioblastoma and review the literature.

The authors present the case of a 38-year-old woman with von Hippel-Lindau disease and a 10-year history of progressive back pain, as well as left lower-extremity pain and numbness. Neurological examination revealed decreased sensation in the left S-1 and S-2 dermatomes. Magnetic resonance imaging demonstrated a large enhancing lesion in the sacral region, with associated erosion of the sacrum. The patient underwent arteriography and embolization of the tumor and then resection. The histopathological diagnosis was consistent with hemangioblastoma and showed intrafascicular tumor infiltration of the S-2 nerve root. At 1-year follow-up examination, pain had resolved and numbness improved.

Sacral nerve root hemangioblastomas may be safely removed in most patients, resulting in stabilization or improvement in symptomatology. Generally, hemangioblastomas of the sacral nerve roots should be removed when they cause symptoms. Because they originate from the nerve root, the nerve root from which the hemangioblastoma originates must be sacrificed to achieve complete resection.
\end{abstract}

\section{KEY WORDS • von Hippel-Lindau disease • nerve root • sacrum • spine • hemangioblastoma}

Hemangioblastomas are histologically benign, highly vascular tumors that develop spontaneously or as part of von Hippel-Lindau disease. Hemangioblastomas (sporadic or associated with von Hippel-Lindau disease) can be found throughout the CNS, but sacral hemangioblastomas are extremely rare. ${ }^{12,23}$ Thus, little information exists regarding their prevalence, clinical manifestation, and management. Sporadic and von Hippel-Lindau diseaseassociated hemangioblastomas are histologically identi$\mathrm{cal}$, and despite being classified as benign neoplasms they can cause significant neurological deficits related to their location and size. ${ }^{3}$ Whether they occur sporadically or in relationship to von Hippel-Lindau disease, they can be cured by complete resection. ${ }^{12,13}$

Abbreviations used in this paper: $\mathrm{CNS}=$ central nervous system; $\mathrm{MR}=$ magnetic resonance.

\section{CASE REPORT}

Presentation. von Hippel-Lindau disease was diagnosed in this 38-year-old woman 2 months before admission by genetic testing, which showed a microdeletion in the von Hippel-Lindau syndrome gene allele (chromosome $3 \mathrm{p} 25$ ). She presented with a 10 -year history of progressive low-back pain with radiation into the left lower extremity to the ankle, and numbness in the same distribution. Neurological examination showed decreased sensation in the left S-1 and S-2 dermatomes to light touch and pinprick.

Examination. Magnetic resonance imaging of the CNS revealed a cerebellar, a cervical, and a lumbar hemangioblastoma as well as a large S-2 hemangioblastoma on the left (Fig. 1). Selective spinal arteriography demonstrated the presence of large arterial feeding arteries from the left 
internal iliac artery and outflow via dilated veins of the perispinal plexus (Fig. 1). The feeding arteries were selectively and completely embolized using embospheres and gelfoam. The patient was taken to surgery the day after embolization to undergo resection of the hemangioblastoma.

Operation. The patient was placed prone, and electromyographic electrodes were placed in the pelvic floor, external urinary sphincter, and anal sphincter. Intravesicular pressure monitoring was used to evaluate for detrusor contraction. A partial L-5 and complete S1-3 laminectomies were performed to provide wide bloodless exposure $1 \mathrm{~cm}$ above and below the rostral and caudal margins of the tumor. The S-1 and S-3 nerve roots were identified and isolated from the tumor and the S-2 nerve root from which the tumor originated. The embolized tumor was incised posteriorly and partially debulked with an ultrasonic aspirator. Vessels entering and leaving the tumor capsule were coagulated using bipolar cautery and sharply divided. After stimulation indicated no evidence of motor function in the involved nerve root, the proximal (intra-

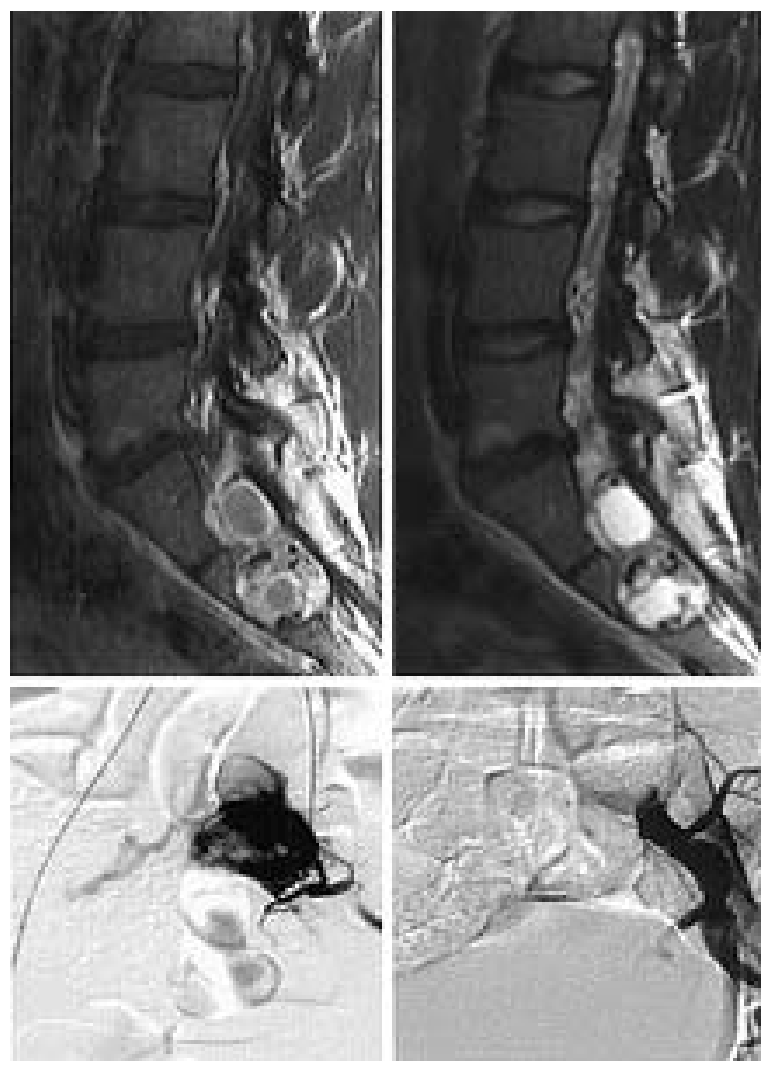

Fig. 1. Sagittal MR images (upper) and arteriograms (lower) of the sacral hemangioblastoma. Upper Left: Postcontrast $\mathrm{T}_{1}$ weighted image demonstrating an enhancing S-2 lesion involving the nerve root and eroding the sacrum. Upper Right: $\mathrm{A}_{2}-$ weighted image demonstrating the S-2 lesion involving the nerve root and eroding the sacrum. Lower Left: Selective arteriogram of a branch of the internal iliac, revealing the highly vascular hemangioblastoma. Lower Right: Nonselective arteriogram of branches of the internal iliac after selective embolization with embospheres and gelfoam, demonstrating devascularization of the hemangioblastoma. dural) and distal (foraminal) ends of the left S-2 nerve root were transected and the remaining tumor was removed. The distal end of the S-2 root was coagulated and the sleeve of the dura around the proximal end of the S-2 root was closed in a watertight fashion. The muscular and cutaneous layers were closed anatomically. Blood loss was less than $100 \mathrm{ml}$.

Postoperative Course. The patient's postoperative course was uncomplicated. Her back and lower-extremity pain resolved. At 1-year follow-up examination, her left S-1 numbness had resolved, and she has residual left S-2 dermatomal numbness.

\section{DISCUSSION}

von Hippel-Lindau Disease

von Hippel-Lindau disease is an autosomal-dominant neoplasia syndrome (MIM 193300) that is the result of a germline mutation or deletion in the von Hippel-Lindau syndrome gene on the short arm of chromosome $3 .{ }^{11}$ Germline mutations in the this gene can result in the development of a number of benign or malignant tumors and cysts in multiple organ systems. ${ }^{12}$ Affected individuals may develop visceral lesions including renal cysts and carcinomas, pheochromocytomas, pancreatic cysts, and neuroendocrine tumors, as well as epididymal and broad ligament cystadenomas. Central nervous system manifestations include retinal, supratentorial, cerebellar, brainstem, and spinal cord hemangioblastomas, as well as endolymphatic sac tumors.

Hemangioblastomas of the CNS are the most common tumor in von Hippel-Lindau disease and can be found in 60 to $80 \%$ of all patients with the disease..$^{5,12,18,23}$ The overall mean age at presentation for CNS hemangioblastomas in von Hippel-Lindau disease is 33 years. ${ }^{23}$ The most common locations for CNS hemangioblastomas are the cerebellum (44-72\%) and the spinal cord (13-50\%), followed by the brainstem (10-20\%), supratentorial region $(<1 \%)$, and lumbosacral nerve roots $(<1 \%){ }^{6,10,12 \text {, }}$ 14,15,19,20,23,24 Although the incidence of lumbosacral nerve root hemangioblastomas is very low in our experience $(>$ 1500 CNS hemangioblastomas evaluated in patients with von Hippel-Lindau disease), we recommend that neuroimaging of the lumbosacral region be performed in patients with von Hippel-Lindau disease with referable (to this anatomical region) signs or symptoms. ${ }^{13}$

\section{Previous Cases}

There are two previously reported cases of sacral nerve root hemangioblastomas. In the first report, Chu, et al., ${ }^{2}$ describe a 24-year-old woman with a von Hippel-Lindau disease-associated S-1 hemangioblastoma (Table 1) who presented with left-sided foot pain. The hemangioblastoma was evident on contrast-enhanced MR imaging, and arteriography revealed that the tumor was supplied via feeding arteries from the internal iliac artery. These feeding vessels were embolized, and the patient underwent complete resection of the hemangioblastoma and associated nerve root. The intraoperative findings and clinical outcome in this patient were not reported. In a report by Hermier, et al., ${ }^{8}$ the authors described a 58-year-old man with a sporadic S-1 hemangioblastoma (Table 1) who present- 
TABLE 1

Summary of the cases involving sacral hemangioblastoma*

\begin{tabular}{|c|c|c|c|c|c|c|c|c|}
\hline Authors \& Year & $\begin{array}{l}\text { Age at Op, } \\
\text { (yrs), Sex }\end{array}$ & $\begin{array}{l}\mathrm{vHL} \\
\text { Disease }\end{array}$ & $\begin{array}{l}\text { Emboli- } \\
\text { zation }\end{array}$ & Presenting Symptoms & Outcome & $\begin{array}{c}\text { Follow } \\
\text { Up } \\
\text { (mos) }\end{array}$ & $\begin{array}{l}\text { Loca- } \\
\text { tion† } \dagger\end{array}$ & $\begin{array}{c}\text { Diam- } \\
\text { eter } \\
(\mathrm{cm}) \S\end{array}$ \\
\hline Chu, et al., 2001 & $24, \mathrm{~F}$ & yes & yes & lt foot pain & NR & NR & S-1 & 2.5 \\
\hline present case & $38, \mathrm{~F}$ & yes & yes & $\begin{array}{l}\text { progressive low-back pain w/ } \\
\text { radiation into lt lower extrem- } \\
\text { ity to ankle; numbness in lt S-1 } \\
\text { \& S-2 dermatomes }\end{array}$ & $\begin{array}{l}\text { pain resolved; S-1 numbness } \\
\text { resolved; residual S-2 numbness }\end{array}$ & 12 & S-2 & 6 \\
\hline
\end{tabular}

\footnotetext{
$* \mathrm{NR}=$ not reported; $\mathrm{vHL}=$ von Hippel-Lindau

$\uparrow$ Vertebral level at which the center of the hemangioblastoma was located.

$\S$ Diameter measured at largest dimension of tumor.
}

ed with a 2-year history of progressive low-back pain, bilateral leg pain, and dysuria. The hemangioblastoma was evident on contrast-enhanced computerized tomography and MR imaging. Arteriography revealed large feeding vessels from the sacral artery. These feeding vessels were embolized, and the patient underwent complete resection of the hemangioblastoma and associated nerve root. Postoperatively, rapid clinical improvement was demonstrated, including resolution of leg pain and weakness, as well as improvement in dysuria.

\section{Present Case}

Associated Symptoms. Similar to the two previous reports of sacral hemangioblastomas (Table 1), our patient presented with back and lower-extremity pain. Similar to reports of patients with lumbar nerve root hemangioblastomas, ${ }^{13}$ our patient also experienced dermatomal numbness in the left S-1 and S-2 distribution. The symptomatology in this case was likely due to direct nerve root (S-2) involvement and adjacent (S-1) nerve root compression by the hemangioblastoma.

Imaging Findings. Contrast-enhanced $\mathrm{T}_{1}$-weighted MR imaging of the lumbosacral spine revealed the hemangioblastoma to be a contrast-enhancing mass eroding the sacrum (Fig. 1). Vivid contrast enhancement is characteristic of hemangioblastomas throughout the CNS. Consistent with the highly vascular nature of hemangioblastomas, flow voids can often be seen within large tumors. ${ }^{2,13}$

Intraoperative Findings. Intraoperative monitoring of the hemangioblastoma-involved nerve root may be helpful in defining its function and can assist in determining the feasibility of nerve root sacrifice. If the hemangioblastoma-associated nerve root is a motor root, then intradural exploration with or without debulking may be the best option. We previously reported on a patient with two cauda equina hemangioblastomas, each involving lumbar motor roots. ${ }^{13}$ Dissection of these hemangioblastomas from the motor roots was impossible because of intrafascicular involvement and because nerve root resection would have caused an unacceptable deficit, these lesions were not resected and the patient's symptoms have remained stable. ${ }^{13}$ That these hemangioblastomas have not grown and that symptoms have stabilized underscore the findings of Wanebo, et al., ${ }^{23}$ in which von Hippel-Lindau disease-associated hemangioblastomas were often found to have long periods of arrested growth associated with no further progression of symptoms, thus allowing for the determination of the feasibility of adjuvant treatments such as irradiation.

Selective arteriography followed by embolization proved useful for minimizing blood loss during resection of this large sacral hemangioblastoma. We do not, however, routinely perform arteriography and embolization in a case of CNS hemangioblastomas. Generally, hemangioblastomas in the CNS can be excised in a near bloodless fashion by performing circumferential microdissection outside of the tumor capsule, thus avoiding embolization and its complications, including vessel rupture and inadvertent occlusion of brain or spinal cord nutrient vessels. ${ }^{12,13}$

Histopathological Findings. Histopathological examination in the present case confirmed the diagnosis of hemangioblastoma. The tumor displayed a highly vascular capillary plexus surrounded by morphologically bland, vacuolated stromal cells typical of hemangioblastoma (Fig. 2). Intrafascicular infiltration of the S-2 nerve root was also seen (Fig. 2). This is consistent with previous

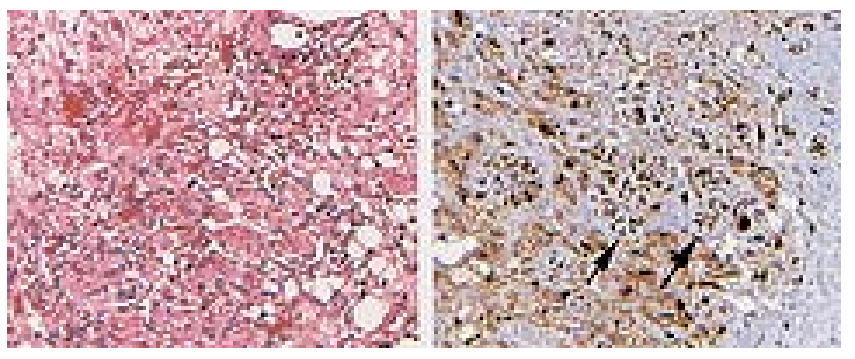

Fig. 2. Photomicrographs of tissue specimens. Left: Classic features of a hemangioblastoma. These include a highly vascular capillary plexus surrounded by morphologically bland, vacuolated stromal cells. Multiple nerve root fascicles can be seen within the hemangioblastoma $(\mathrm{H} \& \mathrm{E}$, original magnification $\times 20)$. Right: Demonstration of S100-positive nerve root fascicles (arrows) within the hemangioblastoma. The tumor cells also stain positive for the S100 antigen. Brown reaction product, original magnification $\times$ 20. (Reprinted from Lonser, et al., J Neurosurg (Spine 1) 99: 64-69, 2003). 
autopsy findings reported by Ismail, et al., ${ }^{9}$ and our previous experience ${ }^{13}$ with cauda equina hemangioblastomas involving the intrafascicular growth of these tumors. Subsequently, the presence of intrafascicular tumor requires sacrifice of the nerve root to achieve complete resection.

Outcome. The numbness and pain in the left $\mathrm{S}-1$ dermatome, which was likely caused by S-2 hemangioblastoma-induced compression of the S-1 nerve root, resolved immediately postoperatively. The patient experiences residual numbness in the S-2 dermatome attributable to the hemangioblastoma-infiltrated nerve root that was resected. This is consistent with the previous reports in which stabilization or improvement in symptoms occurred after resection of lumbar nerve root hemangioblastomas. ${ }^{1,4,7,13}$, $16,17,21,22$

\section{CONCLUSIONS}

Sacral nerve root hemangioblastomas may be safely removed. Generally, hemangioblastomas of the sacral nerve roots should be excised when they become symptomatic. Because it appears that these neoplasms originate from the nerve root (similar to lumbar nerve root hemangioblastomas), it is necessary to sacrifice the nerve root from which the lesion originates to achieve complete resection.

\section{References}

1. Chazono M, Shiba R, Funasaki H, et al: Hemangioblastoma of the L-5 nerve root. Case illustration. J Neurosurg 90:160, 1999

2. Chu BC, Terae S, Hida K, et al: MR findings in spinal hemangioblastoma: correlation with symptoms and with angiographic and surgical findings. AJNR 22:206-217, 2001

3. de la Monte SM, Horowitz SA: Hemangioblastomas: clinical and histopathological factors correlated with recurrence. Neurosurgery 25:695-698, 1989

4. Djindjian M, Djindjian R, Houdart R, et al: Subarachnoid hemorrhage due to intraspinal tumors. Surg Neurol 9:223-229, 1978

5. Filling-Katz MR, Choyke PL, Oldfield E, et al: Central nervous system involvement in Von Hippel-Lindau disease. Neurology 41:41-46, 1991

6. Friedrich CA: Von Hippel-Lindau syndrome. A pleomorphic condition. Cancer 86 (Suppl 11):2478-2482, 1999

7. Giannini C, Scheithauer BW, Hellbusch LC, et al: Peripheral nerve hemangioblastoma. Mod Pathol 11:999-1004, 1998

8. Hermier M, Cotton F, Saint-Pierre G, et al: Myelopathy and sciatica induced by an extradural S1 root haemangioblastoma. Neuroradiology 44:494-498, 2002
9. Ismail SM, Cole G: Von Hippel-Lindau syndrome with microscopic hemangioblastomas of the spinal nerve roots. Case report. J Neurosurg 60:1279-1281, 1984

10. Lamiell JM, Salazar FG, Hsia YE: von Hippel-Lindau disease affecting 43 members of a single kindred. Medicine 68:1-29, 1989

11. Latif F, Tory K, Gnarra J, et al: Identification of the von Hippel-Lindau disease tumor suppressor gene. Science 260: 1317-1320, 1993

12. Lonser RR, Glenn GM, Walther M, et al: von Hippel-Lindau disease. Lancet 361:2059-2067, 2003

13. Lonser RR, Wait SD, Butman JA, et al: Surgical management of lumbosacral nerve root hemangioblastomas in von HippelLindau syndrome. J Neurosurg (Spine 1) 99:64-69, 2003

14. Maddock IR, Moran A, Maher ER, et al: A genetic register for von Hippel-Lindau disease. J Med Genet 33:120-127, 1996

15. Maher ER, Kaelin WG Jr: von Hippel-Lindau disease. Medicine 76:381-391, 1997

16. Milnes JN: The early diagnosis of tumours of the cauda equina. J Neurol Neurosurg Psychiatry 16:158-165, 1953

17. Murota T, Symon L: Surgical management of hemangioblastoma of the spinal cord: a report of 18 cases. Neurosurgery 25: 699-708, 1989

18. Neumann HP, Eggert HR, Scheremet R, et al: Central nervous system lesions in von Hippel-Lindau syndrome. J Neurol Neurosurg Psychiatry 55:898-901, 1992

19. Richard S, Campello C, Taillandier L, et al: Haemangioblastoma of the central nervous system in von Hippel-Lindau disease. French VHL Study Group. J Intern Med 243:547-553, 1998

20. Richard S, David P, Marsot-Dupuch K, et al: Central nervous system hemangioblastomas, endolymphatic sac tumors, and von Hippel-Lindau disease. Neurosurg Rev 23:1-24, 2000

21. Rohde V, Voigt K, Grote EH: Intra-extradural hemangioblastoma of the cauda equina. Zentralbl Neurochir 56:78-82, 1995

22. Sasaki A, Hayakawa I, Tsuchida T, et al: [Hemangioblastoma of the cauda equina - a case report (author's transl).] No Shinkei Geka 6:695-700, 1978

23. Wanebo JE, Lonser RR, Glenn GM, et al: The natural history of hemangioblastomas of the central nervous system in patients with von Hippel-Lindau disease. J Neurosurg 98:82-94, 2003

24. Weil RJ, Lonser RR, DeVroom HL, et al: Surgical management of brainstem hemangioblastomas in patients with von HippelLindau disease. J Neurosurg 98:95-105, 2003

Manuscript received June 13, 2003.

Accepted in final form July 10, 2003.

Address reprint requests to: Russell R. Lonser, M.D., Surgical Neurology Branch, National Institute of Neurological Disorders and Stroke, National Institutes of Health, 10 Center Drive, Building 10, Room 5D37, Bethesda, Maryland 20892-1414. email: lonserr@ ninds.nih.gov. 